\title{
Pomegranate: A promising avenue against the most common chronic diseases and their associated risk factors (Review)
}

\author{
ALESSANDRO LAVORO $^{1}$, LUCA FALZONE ${ }^{2}$, GIUSEPPE GATTUSO ${ }^{1}$, \\ ROSSELLA SALEMI $^{1}$, GIOVANNI CULTRERA ${ }^{1}$, GIAN MARCO LEONE ${ }^{1}$, \\ GIUSEPPA SCANDURRA ${ }^{3}$, SAVERIO CANDIDO ${ }^{1,4}$ and MASSIMO LIBRA ${ }^{1,4}$
}

${ }^{1}$ Department of Biomedical and Biotechnological Sciences, University of Catania, I-95123 Catania;

${ }^{2}$ Epidemiology and Biostatistics Unit, National Cancer Institute - IRCCS 'Fondazione G. Pascale',

I-80131 Naples; ${ }^{3}$ Medical Oncology Unit, Cannizzaro Hospital, I-95126 Catania; ${ }^{4}$ Research Center for

the Prevention, Diagnosis and Treatment of Tumors, University of Catania, I-95123 Catania, Italy

Received March 6, 2021; Accepted April 20, 2021

DOI: $10.3892 / \mathrm{ijfn} .2021 .16$

\begin{abstract}
Pomegranate is an important source of several bioactive compounds with beneficial properties. As widely described in the literature, pomegranate can be considered as a functional food able to promote the maintenance of a good health status. The present review article summarizes the properties of pomegranate, such as antioxidant, anti-inflammatory, anti-aging, prebiotic and anticancer effects, as well as its protective role against metabolic disorders and cardiovascular diseases. Pomegranate and its phytocompounds can prevent the development of several chronic diseases. Additionally, pomegranate can be considered an adjunct for current therapeutic strategies able to improve the standard treatment efficacy and reduce side-effects. However, further studies are required in order to better clarify the mechanisms of action and the synergistic effects of the phytochemicals contained in pomegranate. According to the current data, pomegranate may be a promising avenue against the most common chronic diseases, including cancer.
\end{abstract}

\section{Contents}

1. Introduction

2. Phytochemicals in pomegranate

3. Antioxidant effects

4. Anti-inflammatory effects

5. Anti-aging properties

Correspondence to: Professor Massimo Libra, Department of Biomedical and Biotechnological Sciences, University of Catania, Via Santa Sofia 97, I-95123 Catania, Italy

E-mail: mlibra@unict.it

Key words: pomegranate, natural extracts, cancer, inflammation, cardiovascular diseases, punicalagin, ellagic acid, urolithin A, oxidative stress
6. Protective role of pomegranate in cardiovascular diseases

7. Prebiotic properties

8. Anticancer effects

9. Conclusions

\section{Introduction}

Pomegranate, botanical name Punica granatum L., is a largely consumed fruit deriving from the deciduous tree of Punica L. genus, Punicaceae family (1). This fruit inherits its name from the Latin words 'pomus' and 'granum' (apple with grains), which refer to the consumable portion of the pomegranate tree (2).

Historically, the pomegranate tree dates back to the early bronze age (3500-2000 B.C.) with fossil findings (seeds, leaves and branches) mainly discovered in Central Asia, the Mediterranean area and the Middle East (3). Currently, it is planted in North and South America, the Middle East and Caucasus region, South and Central Asia, North and tropical Africa, as well as in the Mediterranean area, including Sicily (4).

Of note, the pomegranate was considered a symbol of life, symbolizing prosperity and fertility in a number of ancient cultures and religions. For example, the Egyptians considered pomegranate as a symbol of life after death, while in the Bible's Old Testament, it symbolized good luck, abundance and fertility $(1,5)$.

However, pomegranate has been known also for its medical use. Indeed, as described in the literature, pomegranate and its derivatives (fruit, juice, pericarp, seeds and leaves) have a number of therapeutic and pharmacological properties (6), including prebiotic effects (7).

These properties are due to the presence of numerous phytochemicals. Among the known phytocompounds, ellagitannins, gallotannins, anthocyanins, anthocyanidins, flavonoids, flavonones, flavonols, organic acids, fatty acids and lipids, phenolic acids, alkaloids and lignans have been isolated from pomegranate $(8,9)$.

Over the past few years, the attention of the scientific community on the beneficial effects of pomegranate and its 
phytochemicals on human health has increased exponentially, as demonstrated by scientific studies that have been published (10-15). Therefore, in the present review article, the beneficial properties of pomegranate and its potential effects against several pathological conditions that can affect humans are summarized.

\section{Phytochemicals in pomegranate}

As widely reported in the literature, pomegranate represents an important source of beneficial compounds, which play a key role in maintaining homeostasis and a good health status (5,16-18). The natural compounds of pomegranate are described in Fig. 1. The juice, obtained by squeezing the arils, is characterized by lignans, several organic acids, such as gallic and ellagic acid, fatty acids, alkaloids, triterpenoids, phytosterols, hydrolysable tannins and flavonoids $(19,20)$. The pericarp contains hydrolysable tannins, flavonoids, ellagitannins and punicalagins. Several minerals have been isolated from the pericarp, first potassium and phosphorus, followed by sodium, calcium, magnesium and nitrogen $(21,22)$. In addition, the seeds comprise polyphenols, isoflavones and a number of organic acids, including ascorbic, citric and malic acid. They are also characterized by a high content of lipids (punicic, oleic, stearic and palmitic acid) and polyunsaturated fatty acids (linolenic and linoleic acid) $(23,24)$. Finally, pomegranate leaves are rich in tannins, including punicalin and punicafolin, as well as flavone glycosides, such as apigenin and luteolin. Similar to the pericarp, minerals have been also identified in the leaves $(25,26)$. However, it is difficult to establish the specific phytochemical profile of the different parts of pomegranate; indeed, it can be conditioned by various aspects, such as the cultivar, climate, cultivation methods, transformation and the conservation of the processed products $(3,16,27,28)$.

\section{Antioxidant effects}

Several phytochemicals with antioxidant properties have been isolated from edible and non-edible parts of the pomegranate. Among the identified compounds, anthocyanins, ellagic acid and ellagitannins, gallic acid and gallotannins, ferulic acid, catechins, and quercetin are the most represented (29,30). The antioxidant activity of these phytocompounds is mediated via different mechanisms, such as the inhibition of lipid peroxidation, scavenging or neutralizing reactive oxygen species (ROS), activating or inhibiting several signaling pathways and modulating gene expression (31).

Notably, the juice obtained from pomegranate arils is characterized by a higher antioxidant potential compared to other healthy drinks, including red wine, green and black tea, or other natural fruit juices, such as orange, blueberry, black cherry, grape or grapefruit (32-34). Apart from pomegranate juice, other components of pomegranate also exhibit antioxidant activity. Indeed, even the peel and seeds represent an excellent source of natural antioxidants (35). In this regard, several scientific studies have described the antioxidant effects of pomegranate over the past few years.

Tugcu et al (36) (2017) demonstrated the antioxidant properties of pomegranate juice by using a rat model of diabetes. Following 10 weeks of treatment, it was observed that the daily administration of pomegranate juice (100 $\mu$ l per day corresponding to $2.8 \mu \mathrm{mol}$ of total polyphenols per day) significantly reduced the levels of 8-hydroxy-2'-deoxyguanosine $(8 \mathrm{OHdG})$ and malondialdehyde (MDA) compared to the untreated group. Specifically, $8 \mathrm{OHdG}$ and MDA are considered two important tissue indicators for the establishment of DNA oxidative damage and lipid peroxidation, respectively. Moreover, to further evaluate the antioxidant potential of pomegranate juice and its phenolic compounds, the concentration of antioxidant enzymes involved in the response to oxidative stress was measured. Of note, Tugcu et al (36) demonstrated that the activity of reduced glutathione (GSH) and glutathione peroxidase (GSH-Px) was increased following the administration of pomegranate juice, while no statistically significant difference was found for superoxide dismutase (SOD) among the treated and untreated groups. In summary, the study highlights that the daily intake of $100 \mu \mathrm{l}$ of pomegranate juice exerts a marked antioxidant effect in diabetic rats, suggesting that pomegranate and its bioactive compounds may be useful for the maintenance of a good general health status. However, further studies are required to better understand the mechanisms of action of pomegranate juice phytochemicals (36).

Subsequently, Liu et al (37) (2019) conducted an in vitro study to evaluate the antioxidant potential of punicalagin and ellagic acid, two of the most important phytochemicals contained in pomegranate, and urolithin A, a gastrointestinal metabolite deriving from the metabolism of these compounds. Specifically, the authors of the mentioned study used a pomegranate extract with a total polyphenol content of $61.5 \%$ and standardized to punicalagin $(\sim 30 \%)$ and ellagic acid $(\sim 2.3 \%)$, while urolithin A was synthesized in their laboratory. On this basis, they described that treatment with pomegranate extract $(12.5,25$ and $50 \mu \mathrm{g} / \mathrm{ml})$, punicalagin and ellagic acid (12.5, 25 and $50 \mu \mathrm{M}$ ) significantly inhibited the production of ROS in human keratinocyte cells in a concentration-dependent manner. On the other hand, treatment with urolithin A (25 and $50 \mu \mathrm{M})$, punicalagin $(25$ and $50 \mu \mathrm{M})$ and pomegranate extract ( 25 and $50 \mu \mathrm{g} / \mathrm{ml}$ ) significantly increased cell viability. In addition, in order to further investigate the mechanisms of action of pomegranate phenols, Liu et al (37) focused on their potential anti-apoptotic effect and the activation/inhibition of caspase-3/7, -8 and -9 , known as proteolytic enzymes essential for the apoptotic process. They observed that the reduction in the number of apoptotic cells was strictly related to treatment. However, among the considered caspases, only caspase-3 was downregulated by pomegranate extract $(50 \mu \mathrm{g} / \mathrm{ml})$, punicalagin $(50 \mu \mathrm{M})$ and urolithin $\mathrm{A}(50 \mu \mathrm{M})$. Overall, the results obtained from their in vitro study suggested that the phenolic compounds derived from pomegranate and urolithin A exerted a synergistic effect in reducing the cellular toxicity caused by oxidative stress (37).

Notably, in 2020, Morittu et al (38) performed an in vitro and in vivo study to explore whether the purification of pomegranate juice could ameliorate the already known antioxidant properties of this fruit by using a polyvinylidene fluoride fiber. In the in vitro $\beta$-carotene bleaching test, natural and clarified juices were tested at concentrations of $0.5-100 \mu \mathrm{g} / \mathrm{ml}$. Specifically, despite a lower amount of phenols, the filtered juice exhibited a higher antioxidant activity $\left(\mathrm{IC}_{50}, 19.7 \mu \mathrm{g} / \mathrm{ml}\right.$ following $30 \mathrm{~min}$ of incubation) compared to the natural juice 


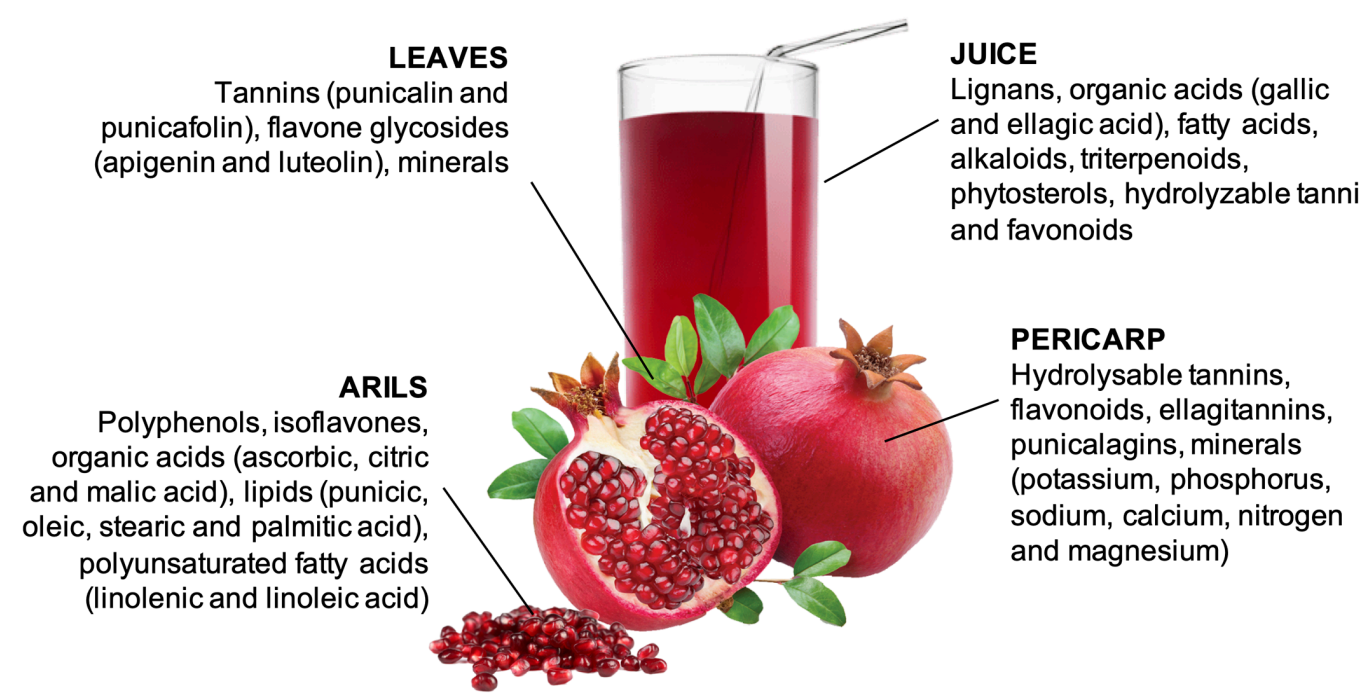

Figure 1. The natural compounds of pomegranate.

( $\mathrm{IC}_{50}, 51.5 \mu \mathrm{g} / \mathrm{ml}$ following $30 \mathrm{~min}$ of incubation). At the same time, the processed juice inhibited the release of $\alpha$ glucosidase $(\alpha-\mathrm{GLU})$ enzyme more than the natural product $\left(\mathrm{IC}_{50}, 68.6\right.$ and $80.1 \mu \mathrm{g} / \mathrm{ml}$, respectively) (38). Since $\alpha$-GLU is an important enzyme implicated in the digestive process of mono- and polysaccharides, these results suggest that the purification may also improve the hypoglycemic action of pomegranate. In the in vivo study (mouse model), $500 \mathrm{mg} / \mathrm{kg}$ of body weight of purified or natural juice dissolved into $0.2 \mathrm{ml}$ of water were daily administered for 28 days. Specifically, the purified product reduced oxidative stress more than the unfiltered juice, as demonstrated by the reduction of reactive oxygen metabolites (d-ROMs). In addition, the processed juice induced a significant decrease in the levels of different markers for hepatic and heart damage, such as alanine aminotransferase (ALT), aspartate aminotransferase (AST) and creatine-phosphokinase (CPK). The obtained data further underline the benefits of pomegranate in maintaining homeostasis and health status. Moreover, these results suggest that the filtration system could be useful to enhance the beneficial effects of pomegranate (38).

\section{Anti-inflammatory effects}

Inflammation represents the first defensive barrier of the human immune system against foreign agents and tissue damage. It occurs through two steps, acute and chronic. However, when inflammation persists and becomes chronic, it can be harmful to the body (39). Indeed, it has been shown that chronic inflammation is involved in the onset of several inflammatory disorders and chronic diseases, such as inflammatory bowel disease, rheumatoid arthritis and chronic obstructive pulmonary disease $(40,41)$. At the same time, dysfunctional inflammatory responses have been implicated in the development of other non-communicable diseases, including obesity, diabetes, insulin resistance, atherosclerosis and illnesses affecting the nervous system (42).

Over the years, a number of scientific studies have highlighted an inverse association between a diet rich in fruits and vegetables and the onset of chronic diseases $(43,44)$. Therefore, the scientific community has paid increasing attention on these functional foods due to their ability to maintain systemic health through their bioactive compounds $(45,46)$. In this context, an increasing number of researchers have examined the anti-inflammatory effects of pomegranate and its derivatives.

The anti-inflammatory potential of punicalagin and ellagic acid, identified as the main components of pomegranate pericarp polyphenols (464.48 and $71.50 \mathrm{mg} / \mathrm{g}$, respectively), was previously investigated through an in vitro study (47). Specifically, the research group incubated a murine macrophage cell line (RAW264.7) with several concentrations of punicalagin $(0-100 \mu \mathrm{M})$, ellagic acid $(0-100 \mu \mathrm{M})$ and pomegranate pericarp polyphenols $(0-200 \mu \mathrm{g} / \mathrm{ml}$ with a polyphenol content of 57.09\%). Following treatment, it was observed that all the tested polyphenols significantly reduced the release of nitric oxide (NO) and prostaglandin $\mathrm{E}_{2}\left(\mathrm{PGE}_{2}\right)$, two important mediators generally upregulated in inflammatory processes, in a concentration-dependent manner. Similarly, all treatments also decreased the production of inducible nitric oxide synthase (iNOS) and cyclooxygenase 2 (COX-2), two enzymes that play a key role in promoting inflammation (47). The release of pro-inflammatory cytokines was also evaluated in the same cell line. Specifically, it was observed that the release of tumor necrosis factor $\alpha$ (TNF- $\alpha)$, interleukin (IL)-1 $\beta$ and IL- 6 was significantly decreased following treatment with pomegranate phytocompounds. Finally, the effects of pomegranate on the activation/inhibition of mitogen-activated protein kinases (MAPKs) pathway were also investigated. A significant reduction in the extracellular-signal-regulated kinase (ERK), Jun N-terminal kinase (JNK) and p38 MAPK expression levels was observed following polyphenol treatment. The mentioned in vitro study highlights that even the non-edible parts of pomegranate have an anti-inflammatory potential, suggesting that pomegranate pericarp may be useful for the development of novel natural treatments against inflammatory processes (47).

Similarly, the anti-inflammatory properties of phenolic compounds that characterize pomegranate pericarp (punicalagin, gallic and ellagic acid) and their mechanisms of action 
were previously investigated (48). Briefly, the researchers used increasing concentrations of pomegranate pericarp extract (1.0, $2.5,5.0,10$ and $25 \mu \mathrm{g} / \mathrm{ml}$ ) to perform an in vivo and ex vivo study. The treatment with pericarp extract led to a significant reduction in the secretion of $\mathrm{C}-\mathrm{X}-\mathrm{C}$ motif chemokine ligand 8 (CXCL8) in both the human colorectal adenocarcinoma model (Caco-2 cells) and mammalian intestinal model (porcine colonic tissues) at all tested concentrations (48). This result further confirms the anti-inflammatory activity of pomegranate; indeed, CXCL8, also known as IL-8, is a cytokine predominantly implicated as a chemoattractant towards neutrophils under inflammatory conditions. In addition, to elucidate the mechanisms of action of phytochemicals deriving from pomegranate pericarp, the authors of the study evaluated the expression of different cytokines involved in inflammatory process (48). Of note, the expression levels of IL-1A and IL-6 were significantly decreased in the treated colonic tissues compared to the control in a concentration-dependent manner. Overall, the study highlights that pomegranate pericarp extract has high anti-inflammatory properties, particularly at the concentration of $5 \mu \mathrm{g} / \mathrm{ml}$, suggesting that it may play a key role in modulating inflammatory bowel diseases (48).

Recently, Pepe et al (49) (2020) evaluated the beneficial properties of pomegranate juice extract, not only against inflammatory processes, but also following treatment with 5-fluorouracil, whose toxic profile on the intestinal epithelial tissue was already reported. Through an in vitro study on a rat intestinal epithelial cell line, the investigators analyzed the release of cytokines and enzymes involved during the inflammatory status. Specifically, treatment with juice extract $(10-1.25 \mu \mathrm{g} / \mathrm{ml})$ decreased the concentration of TNF- $\alpha$, IL-6 and IL-1 $\beta$, as well as the expression of COX-2 and iNOS at all tested concentrations (49). Under both study conditions, the antioxidant and anti-inflammatory capacity of pomegranate juice extract was further demonstrated by the reduction in oxidative stress and the increase in the levels of cytoprotective enzymes, such as heme oxygenase 1 (HO-1) and NAD(P)H dehydrogenase quinone 1 (NQO-1), and tight junction proteins, such as claudin 1 (CLDN-1) and zonula occludens 1 (ZO-1). The authors of that study also demonstrated that pomegranate extract may play an important role as an adjuvant for anticancer therapy. Accordingly, the phenomenon of apoptosis decreased following treatment with juice extract in rat intestinal epithelial cell line damaged by 5 -fluorouracil. Therefore, it can be hypothesized that in colon cancer patients, the integration of pomegranate juice extract with 5-fluorouracil could regularly induce the apoptosis of cancer cells and prevent side-effects caused by chemotherapy, such as inflammation and intestinal damage. However, further studies are necessary in order to better understand the potential use of pomegranate as an adjuvant for chemotherapy (49).

\section{Anti-aging properties}

Aging is a biological process that plays a key role in the development of several pathological conditions, such as neurodegenerative diseases or osteoporosis (50-52). The main cause of neurodegenerative diseases is represented by a progressive loss of brain cells associated with the deposition of proteins with altered physicochemical properties, known as misfolded proteins (53). The proteins involved in the pathogenesis of the main neurodegenerative diseases are $\beta$-amyloid in Alzheimer's disease, $\alpha$-synuclein in Parkinson's disease, huntingtin (HTT) in Huntington's disease, prion protein (PrP) in Creutzfeldt-Jacob's disease and superoxide dismutase-1 (SOD1) in amyotrophic lateral sclerosis (54).

Generally, the clinical manifestations are evidenced after a certain period from the onset of these pathologies; therefore, it is important to not only develop novel effective treatments for the diagnosed cases, but also novel effective strategies for prevention. Over the past decade, a number of studies have proposed the use of pomegranate and its derivatives as a potential adjuvant for the prevention of neurodegenerative disorders.

Braidy et al (55) (2016) explored the anti-aging properties of pomegranate in a mouse model of Alzheimer's disease. Specifically, mice were fed a regular diet containing $4 \%$ of pomegranate extract and after 4 months the research group observed that daily supplementation with pomegranate enhanced the expression of synaptic structural proteins, typically expressed at low levels in such diseases, including postsynaptic density protein 95 (PSD-95), synaptosomal associated protein 25 (SNAP25), synaptophysin, phosphorylated calcium/calmodulin-dependent protein kinase (p-CaMKII $\alpha / \mathrm{CaMKII} \alpha$ ), phosphorylated cyclic AMP-response element-binding protein (pCREB/CREB), along with brain-derived neurotrophic factor (BDNF) and insulin-like growth factor 1 (IGF-1) (55). Of note, pomegranate also decreased the neuroinflammatory activity, as demonstrated by a low release of TNF- $\alpha$, IL- $1 \beta$, iNOS, C-C motif chemokine ligand 2 (CCL2) and IL-10 pro-inflammatory cytokines. Finally, it was observed that pomegranate ameliorated the synaptic function through the activation of phosphatidylinositol 3-kinase (PI3K)/protein kinase B (Akt)/mammalian target of rapamycin (mTOR) signaling pathway. This finding was also confirmed by the reduction in the $\beta$-secretase, soluble amyloid protein procurer $\beta$ (sAPP $\beta$ ) and carboxyl-terminal fragment $\beta$ (CTF $\beta$ ) expression levels. In summary, Braidy et al (55) demonstrated that a regular daily diet supplemented with $4 \%$ of pomegranate extract reduced the progression of Alzheimer's disease in mice, suggesting that long-term supplementation with pomegranate may represent a natural adjuvant for the treatment of this neurodegenerative disease.

In another study, a rat model of Parkinson's disease was used to evaluate the effects of pomegranate juice (56). The authors of that study demonstrated that the daily intake of pomegranate juice $(500 \mathrm{mg} / \mathrm{kg}$ of body weight) significantly reduced both the impairment of the postural reflexes and the loss of neural cells, two characteristic aspects of this disease. At the same time, pomegranate juice exhibited antioxidant and anti-inflammatory properties, as demonstrated by the reduction in the levels of ROS, as well as the increase in mitochondrial aldehyde dehydrogenase 2 (ALDH2) and antioxidant enzyme activity. In addition, to further confirm the neuroprotective effects of pomegranate juice, the research group detected the level of $\alpha$-synuclein, whose deposition on neurons represents one of the main causes of Parkinson's disease. Of note, the administration of pomegranate juice reduced $\alpha$-synuclein accumulation in the treated rats compared to the untreated ones (56). Overall, the obtained results highlight the poten- 
tial of pomegranate juice to attenuate Parkinson's disease in rats, indicating that daily supplementation of pomegranate juice may play a key role against this pathology. However, further studies are required in order to completely understand the mechanisms of action of phytocompounds contained in juice (56).

Osteoporosis is an age-related disease characterized by the progressive degeneration of bone tissue and a reduction in bone mass, which cause a higher frequency in bone fractures compared to normal conditions $(57,58)$. Due to the increase in the aging rate, osteoporosis represents a main concern for the population worldwide, which affects females more frequently than males (59).

Currently, the gold standard strategies for the treatment and prevention of this disease are based on calcium and vitamin D intake. In this context, previous research has demonstrated a strong interest in the bioactive compounds derived from fruits and vegetables, in order to improve the efficacy of the available treatments (60). Among the main dietary sources of micronutrients, over the last few years, researchers have focused on pomegranate to evaluate the activity of its phytochemicals (flavonoids, anthocyanins and tannins) against this age-related disease.

In 2014, Spilmont et al (61) investigated the beneficial properties of pomegranate bioactive compounds in a mouse model of osteoporosis. Briefly, mice were fed a standard diet supplemented with $5.7 \%$ of pomegranate lyophilized totum (corresponding to $1.4 \mathrm{~g}$ per day of fresh totum), $2.9 \%$ of pomegranate lyophilized mashed peel (corresponding to $622 \mu \mathrm{g}$ per day of fresh peel), or $9.6 \%$ of pomegranate fresh juice (corresponding to $550 \mu \mathrm{l}$ per day of juice) for 30 days. Through their in vivo study, the researchers found that all the used diets supplemented with pomegranate were able to contrast the loss of bone mineral density induced by osteoporosis. This result was demonstrated by the positive association between pomegranate administration, the maintenance of bone volume/surface ratio and the reduction of tissue porosity (61). In addition, in order to better understand the mechanisms of action, the research group focused on the expression of main osteoclastic and osteoblastic markers. Specifically, Spilmont et al (61) noted that pomegranate induced a downregulation in the expression of calcitonin receptor (CTR). As regards osteoblast activity, the expression of low-density lipoprotein receptor-related protein 5 (LRP5), a co-receptor involved in the Wnt/ $\beta$-catenin signaling pathway, was enhanced by pomegranate. According to that study, pomegranate represents a functional food with several heath properties. For example, these results highlight that all pomegranate derivatives (juice, peel and totum) play a key role in the maintenance of bone health, reducing osteoporosis caused by ovariectomy in mice (61).

Recently, Wang et al (62) (2020) conducted an in vitro and in vivo study to analyze the effects of punicalagin, one of the most abundant polyphenols contained in pomegranate, against osteoporosis. Using a murine macrophage cell line, the researchers observed that punicalagin $(5,10,20$ and $50 \mu \mathrm{M})$ was able to reduce the osteoclastogenesis process and decrease bone reabsorption in a dose-dependent manner. These findings were mediated via the downregulation in the expression of genes involved in osteoclast differentiation, such as acid phosphatase 5 (Acp5), osteoclast-associated receptor (OSCAR),
ATPase $\mathrm{H}^{+}$transporting V0 subunit D2 (Atp6v0d2), dendritic cell-specific transmembrane protein (DC-STAMP), cathepsin $\mathrm{K}$ (CTSK) and matrix metallopeptidase (MMP)-9. In addition, this phenolic compound also exerted its inhibitory effects on nuclear factor- $\kappa \mathrm{B}(\mathrm{NF}-\kappa \mathrm{B})$ and the MAPK pathway, both important for osteoclastogenesis. In the in vivo study, Wang et al (62) used a mouse model of osteoporosis and obtained similar results to the study by Spilmont et al (61). Indeed, treatment with punicalagin $(50 \mathrm{mg} / \mathrm{kg}$ of body weight) preserved not only bone volume/surface ratio, but also the loss of bone density. The obtained data further confirm the importance of pomegranate in maintaining the health status, suggesting that punicalagin may play a critical role in the prevention and treatment of skeletal tissue-related disorders (62).

The antioxidant, anti-inflammatory and anti-aging effects of pomegranate derivatives and bioactive compounds are summarized in Table I.

\section{Protective role of pomegranate in cardiovascular diseases}

Cardiovascular diseases, commonly defined as disorders of the heart and vessels, represent the main cause of morbidity and mortality worldwide (63). As widely described, a number of risk factors are involved in the development of cardiovascular diseases, for example, high blood pressure, hyperlipidemia, especially hypercholesterolemia and atherosclerosis, smoking, sex, age, obesity, diabetes, a sedentary lifestyle, an unhealthy diet, poverty, family history and genetic predisposition (64).

In this context, several studies have demonstrated that a healthy lifestyle, characterized by a diet rich in fruits and vegetables, is positively associated with a lower risk of developing cardiovascular disorders $(65,66)$. These beneficial effects are due to a wide spectrum of bioactive compounds found in fruits and vegetables; for example, vitamins, antioxidants, folates and phytochemicals, such as carotenoids and polyphenols $(67,68)$. In this field, recent clinical trials and in vivo/in vitro studies have highlighted that pomegranate can help to prevent several risk factors and promote cardiovascular health.

Stockton et al (69) (2017) conducted a randomized double-blinded clinical trial in order to evaluate the beneficial effects of pomegranate in maintaining cardiovascular and systemic health. Healthy volunteers were divided into two groups (1 capsule per day of the placebo or pomegranate extract containing $210 \mathrm{mg}$ of punicalagin, $328 \mathrm{mg}$ of other pomegranate polyphenols, such as flavonoids and ellagic acid, and 0-37 mg of anthocyanins) and different vital signs were detected before, during (4 weeks) and at the end of the study period ( 8 weeks). Specifically, the values of anthropometric indicators, including body weight, lean and fat mass, waist and hip circumference, exhibited no statistically significant differences among the two groups (69). As regards blood pressure, although systolic blood pressure exhibited similar values in both the placebo and pomegranate groups, on the contrary, the reduction in diastolic blood pressure differed significantly following pomegranate phenol intake. In summary, the mentioned clinical trial highlights the effect of pomegranate in reducing diastolic blood pressure and suggests that its phenolic compounds could play a key role in the prevention of some cardiovascular risk factors, such as hypertension (69). 
Table I. Antioxidant, anti-inflammatory and anti-aging effects of pomegranate derivatives and its phytochemicals.

\begin{tabular}{|c|c|c|c|c|}
\hline Disease model & Study typology & $\begin{array}{c}\text { Pomegranate } \\
\text { derivatives/phytochemicals }\end{array}$ & Effects & (Refs.) \\
\hline Diabetes & In vivo (rat) & Pomegranate juice & $\begin{array}{l}\downarrow: 8 \mathrm{OHdG}, \mathrm{MDA} \\
\uparrow: \text { GSH, GSH-Px }\end{array}$ & $(36)$ \\
\hline Oxidative stress & In vitro $(\mathrm{HaCaT}$ cells) & $\begin{array}{l}\text { Pomegranate extract, } \\
\text { punicalagin, ellagic acid, } \\
\text { urolithin A }\end{array}$ & $\begin{array}{l}\downarrow: \text { ROS, capase-3 } \\
\uparrow: \text { cell viability }\end{array}$ & $(37)$ \\
\hline N/A & $\begin{array}{l}\text { In vitro (DPPH, FRAP, } \\
\beta \text {-carotene bleaching tests); } \\
\text { in vivo (mouse) }\end{array}$ & $\begin{array}{l}\text { Natural/clarified } \\
\text { pomegranate juice }\end{array}$ & $\begin{array}{l}\downarrow: \alpha-G L U, d-R O M s, \\
\text { ALT, AST, CPK }\end{array}$ & $(38)$ \\
\hline Inflammation & In vitro (RAW 264.7 cells) & $\begin{array}{l}\text { Pomegranate peel } \\
\text { polyphenols, punicalagin, } \\
\text { ellagic acid }\end{array}$ & $\begin{array}{l}\downarrow: \text { NO, } \text { PGE }_{2}, \text { iNOS, COX-2, } \\
\text { TNF- } \alpha, \text { IL-1 } \beta, \text { IL-6, ERK, } \\
\text { JNK, p38 MAPK }\end{array}$ & $(47)$ \\
\hline $\begin{array}{l}\text { Colorectal } \\
\text { adenocarcinoma, } \\
\text { inflammation }\end{array}$ & $\begin{array}{l}\text { In vitro (Caco- } 2 \text { cells), } \\
\text { ex vivo (porcine } \\
\text { colonic tissues) }\end{array}$ & Pomegranate peel extract & $\downarrow:$ IL-8, IL-1A, IL-6 & $(48)$ \\
\hline $\begin{array}{l}\text { Inflammation, } \\
\text { tissue injury }\end{array}$ & In vitro (IEC-6 cells) & Pomegranate juice extract & $\begin{array}{l}\downarrow: \text { TNF- } \alpha, \text { IL-6, IL-1 } \beta, \text { iNOS, COX-2 } \\
\uparrow: \text { HO-1, NQO-1, CLDN-1, ZO-1 }\end{array}$ & $(49)$ \\
\hline Alzheimer's disease & In vivo (mouse) & Pomegranate extract & $\begin{array}{l}\downarrow: \text { TNF- } \alpha, \text { IL-1 } \beta, \text { iNOS, CCL2, } \\
\text { IL-10, } \beta \text {-secretase, sAPP } \beta, \text { CTF } \beta \\
\uparrow: \text { PSD-95, SNAP25, synaptophysin, } \\
\text { p-CaMKII } \alpha / \text { CaMKII } \alpha, \text { IGF-1, } \\
\text { p-CREB/CREB, BDNF }\end{array}$ & $(55)$ \\
\hline Parkinson's disease & In vivo (rat) & Pomegranate juice & $\begin{array}{l}\downarrow: \text { Impairment of the postural } \\
\text { reflexes, loss of nervous cells, } \\
\text { ROS, } \alpha \text {-synuclein accumulation } \\
\uparrow: \text { ALDH } 2, \text { antioxidant enzymes }\end{array}$ & $(56)$ \\
\hline Osteoporosis & In vivo (mouse) & $\begin{array}{l}\text { Pomegranate lyophilized } \\
\text { mashed totum/peel, } \\
\text { pomegranate juice }\end{array}$ & $\begin{array}{l}\downarrow: \text { Tissue porosity, CTR } \\
\uparrow: \text { LRP5 maintenance of bone } \\
\text { volume/surface ratio }\end{array}$ & $(61)$ \\
\hline Osteoporosis & $\begin{array}{l}\text { In vitro (RAW } 264.7 \text { cells), } \\
\text { in vivo (mouse) }\end{array}$ & Punicalagin & $\begin{array}{l}\downarrow: \text { Acp5, OSCAR, Atp6v0d2, } \\
\text { DC-STAMP, CTSK, MMP-9, } \\
\text { NF- } \mathrm{B}, \text { MAPKs pathway } \\
\text { maintenance of bone } \\
\text { volume/surface ratio }\end{array}$ & $(62)$ \\
\hline
\end{tabular}

8OHdG, 8-hydroxy-2'-deoxyguanosine; $\alpha$-GLU, $\alpha$ glucosidase; Acp5, acid phosphatase 5; ALDH2, mitochondrial aldehyde dehydrogenase 2; ALT, alanine amino-transferase; AST, aspartate amino-transferase; Atp6v0d2, ATPase $\mathrm{H}^{+}$transporting V0 subunit D2; BDNF, brain-derived neurotrophic factor; CCL2, C-C motif chemokine ligand 2; CLDN-1, claudin 1; CPK, creatine-phosphokinase; COX-2, cyclooxygenase 2; CTF $\beta$, carboxyl-terminal fragment $\beta$; CTR, calcitonin receptor; CTSK, cathepsin K; DC-STAMP, dendritic cell-specific transmembrane protein; DPPH, 2,2-diphenil-1-picrylhydrazyl; d-ROMs, reactive oxygen metabolites; ERK, extracellular-signal-regulated kinase; FRAP, Ferric-reducing antioxidant power; GSH, reduced glutathione; GSH-Px, glutathione peroxidase; HO-1, heme oxygenase 1; IGF-1, insulin-like growth factor 1; IL-1A, interleukin 1A; IL-1 $\beta$, interleukin 1 $\beta$; IL-6, interleukin 6; IL-8, interleukin 8; IL-10, interleukin 10; iNOS, inducible nitric oxide synthase; JNK, jun N-terminal kinase, LRP5, low-density lipoprotein receptor-related protein 5; MAPKs, mitogen-activated protein kinases; MDA, malondialdehyde; MMP-9, matrix metallopeptidase 9; N/A, not applicable; NF- $\mathrm{B}$, nuclear factor- $\mathrm{kB}$; NO, nitric oxide; NQO-1, NAD $(\mathrm{P}) \mathrm{H}$ dehydrogenase quinone 1; OSCAR, osteoclast-associated receptor; p38 MAPK, mitogen-activated protein kinase p38; p-CaMKII $\alpha / C a M K I I \alpha$, phosphorylated calcium/calmodulin-dependent protein kinase; p-CREB/CREB, phosphorylated cyclic AMP-response element binding protein; $\mathrm{PGE}_{2}$, prostaglandin $\mathrm{E}_{2}$; PSD-95, postsynaptic density protein 95 ; ROS, reactive oxygen species; sAPP $\beta$, soluble amyloid protein procurer $\beta$; SNAP25, synaptosomal associated protein 25 ; TNF- $\alpha$, tumor necrosis factor $\alpha$; ZO- 1 , zonula occludens 1 .

Furthermore, through an in vivo study on mice fed a high-fat diet, Estrada-Luna et al (70) (2018) investigated the effects of pomegranate juice on paraoxonase 1 (PON1) gene expression. PON1 represents an important calcium-dependent glycoprotein attached to high-density lipoprotein (HDL) in blood. Specifically, this glycoprotein has anti-atherogenic properties and decreased levels of PON1 are associated with higher levels of cholesterol (71). In the study by Estrada-Luna et al (70), it was observed that the daily intake of pomegranate juice (300 $\mu \mathrm{l}$ containing $0.35 \mathrm{mmol}$ of total polyphenols) increased the expression levels of PON1 in obese mice. On the other hand, the total serum cholesterol levels were significantly 
Table II. Cardiovascular protective effects of pomegranate derivatives and its phytochemicals.

\begin{tabular}{llll}
\hline Disease model & \multicolumn{1}{c}{ Study typology } & Pomegranate derivatives/phytochemicals & \multicolumn{1}{c}{ Effects } \\
\hline N/A & $\begin{array}{l}\text { Clinical trial } \\
\text { (healthy volunteers) } \\
\text { In vivo (mouse) }\end{array}$ & Pomegranate extract & $\begin{array}{l}\downarrow \text { : Diastolic blood pressure } \\
\text { Obesity }\end{array}$ \\
Obesity/diabetes & $\begin{array}{l}\text { In vitro } \\
\text { (3T3-L1 cells) }\end{array}$ & Pomegranate juice & $\begin{array}{l}\downarrow \text { : Serum cholesterol levels } \\
\uparrow: \text { PON1 }\end{array}$ \\
& & Pomegranate juice, ellagic acid, & $\downarrow$ : Lipase, $\alpha-G L U$, DPP-4, \\
& & punicalagin, urolithin A & (75) \\
& & & $\begin{array}{l}\text { triglyceride accumulation, } \\
\text { adiponectin, PPAR } \gamma, \text { GLUT4, } \\
\text { FABP4 }\end{array}$
\end{tabular}

$\alpha$-GLU, $\alpha$ glucosidase; DPP-4, dipeptidyl peptidase 4; FABP4, fatty acid binding protein 4; GLUT4, glucose transporter type 4; N/A, not applicable; PON1, paraoxonase 1; PPAR $\gamma$, peroxisome proliferator-activated receptor $\gamma$.

reduced after 5 months of pomegranate treatment $(\sim 210 \mathrm{mg} / \mathrm{dl}$ in mice fed a high-fat diet, $\sim 160 \mathrm{mg} / \mathrm{dl}$ in mice fed a high-fat diet supplemented with pomegranate juice, $\sim 140 \mathrm{mg} / \mathrm{dl}$ in mice fed a normal diet) (70). The capability of pomegranate and its bioactive compounds to enhance PON1 expression and to reduce total cholesterol has also been demonstrated in other previous studies (72-74). Overall, these data underline that bioactive compounds contained in pomegranate juice may play a certain role in preventing cardiovascular risk factors, including atherosclerosis and obesity (70).

In the same year, Les et al (75) used a murine pre-adipocytes cell line (3T3-L1) in order to study the association between cardiovascular risk factors and pomegranate. Briefly, they treated 3T3-L1 cells with pomegranate juice (50 and $100 \mu \mathrm{g} / \mathrm{ml})$, its phenolic compounds punicalagin and ellagic acid (10 and $20 \mu \mathrm{M}$, 10 and $50 \mu \mathrm{M}$, respectively), as well as urolithin $\mathrm{A}(10$ and $50 \mu \mathrm{M})$. Notably, the research group observed that the release of lipase, $\alpha$-GLU and dipeptidyl peptidase 4 (DPP-4) enzymes was significantly decreased by the action of all tested samples in a concentration-dependent manner. These properties were confirmed by the reduction of adipocyte differentiation and triglyceride accumulation, particularly in the treatments with punicalagin and urolithin A (75). Finally, to further understand the mechanisms of action of these compounds, Les et al (75) observed that pomegranate phytochemicals modulated the gene expression of some important regulators for the metabolism of glucose and fatty acids, specifically adiponectin, peroxisome proliferator-activated receptor $\gamma(\operatorname{PPAR} \gamma)$, glucose transporter type 4 (GLUT4) and fatty acid binding protein 4 (FABP4). The modulatory effect on these markers of adipocyte differentiation was particularly observed following punicalagin and urolithin A treatment. The results obtained from that in vitro study further confirm the beneficial properties of pomegranate phytochemicals, suggesting that pomegranate may reduce the risk of obesity and diabetes (75).

The protective role of pomegranate against cardiovascular diseases and associated risk factors is summarized in Table II.

\section{Prebiotic properties}

The intestinal microbiota is defined as an important symbiotic partner of the human body in maintaining general health. It is characterized by several species of microorganisms, which play a key role in many biological processes, first digestive process and energy regulation, as well as vitamin and fatty acids synthesis, defense toward infectious process and the development of immune defenses (76-78).

However, the dysbiosis of intestinal microbiota seems to be related to the onset of various pathological conditions, such as obesity, diabetes, cancer, allergies and inflammatory diseases (79-81). Over the past few years, an increasing number of studies have highlighted that micronutrients derived from a healthy diet are critical for the preservation of balanced gut microbiota and health status $(82,83)$. In this regard, it is interesting to note that ellagitannins, the most abundant polyphenols of pomegranate, are hydrolyzed in ellagic acid in the gut prior to being further metabolized by microbiota yielding urolithin $\mathrm{A}$ and $\mathrm{B}$, two bioactive compounds with numerous beneficial properties $(84,85)$.

In this field, a number of recent studies have paid attention on the interaction between gut microbiota and polyphenols derived from pomegranate in order to obtain a better understanding of the prebiotic potential of pomegranate and its derivatives.

For example, in 2015, Li et al (86) examined whether pomegranate was able to modulate the bacterial composition of gut microbiota. Specifically, the research group conducted an in vitro study on fecal cultures, evaluating the relative abundance of main microorganisms that populate the intestine, such as Enterobacteriaceae, the Bacteroides fragilis group, Clostridiaceae, Bifidobacterium and Lactobacillus. Notably, treatment with pomegranate extract and pomegranate juice ( 25 and $100 \mu \mathrm{g} / \mathrm{ml}$ ) significantly enhanced the amount of both Bifidobacterium and Lactobacillus. On the other hand, the concentration of the Bacteroides fragilis group, Clostridiacae and Enterobacteriaceae was reduced by pomegranate in a concentration-dependent manner (86). Moreover, in order to better understand the impact of pomegranate on bacterial growth, Li et al (86) analyzed which of the phenolic compounds was metabolized by Bifidobacterium and Lactobacillus. Specifically, ellagic acid and glycosyl ellagic acid were the most used phenols in both cases, whereas punicalin was not metabolized in general, apart from the bacterial strain ATCC 
Table III. Anticancer effects of pomegranate derivatives and its phytochemicals.

\begin{tabular}{|c|c|c|c|c|}
\hline Tumor model & Study typology & $\begin{array}{c}\text { Pomegranate } \\
\text { derivatives/phytochemicals }\end{array}$ & Effects & (Refs.) \\
\hline Breast & In vivo (rat) & Pomegranate emulsion & $\downarrow$ : ER- $\alpha$, ER- $\beta, \beta$-catenin, cyclin D1 & $(97)$ \\
\hline Lung & $\begin{array}{l}\text { In vitro }(\mathrm{A} 549, \mathrm{H} 1299, \\
\mathrm{LL} / 2 \text { cells) }\end{array}$ & Pomegranate leaves extract & $\begin{array}{l}\downarrow: \text { ROS }, \Delta \Psi \mathrm{m}, \mathrm{MMP}-2, \mathrm{MMP}-9 ; \\
\text { arrest of cell cycle in } \mathrm{G} 2 / \mathrm{M} \text { phase }\end{array}$ & $(98)$ \\
\hline Prostate & $\begin{array}{l}\text { In vitro }(\mathrm{DU} 145, \mathrm{PC} 3 \text {, } \\
\text { TRAMP-C1 cells) }\end{array}$ & Pomegranate peel extract & $\begin{array}{l}\downarrow: \mathrm{Bcl} 2, \mathrm{MMP}-2, \mathrm{MMP}-9 \\
\uparrow: \mathrm{Bax}\end{array}$ & $(99)$ \\
\hline Colorectal & In vitro (HCT 116 cells) & Punicalagin & $\begin{array}{l}\downarrow: \text { Cell viability of tumor cells } \\
\text { in } S \text { phase of cell cycle, Anx-A1 }\end{array}$ & $(100)$ \\
\hline
\end{tabular}

Anx-A1, Annexin A1; Bax, BCL2-associated X protein; Bcl2, B-cell lymphoma 2; $\Delta \Psi \mathrm{m}$, mitochondrial membrane potential; ER- $\alpha$, estrogen receptor $\alpha$; ER- $\beta$, estrogen receptor $\beta$; MMP-2, matrix metallopeptidase 2; MMP-9, matrix metallopeptidase 9; ROS, reactive oxygen species .

15703 Bifidobacterium adolescentis. These results highlight the capability of pomegranate polyphenols to restore the correct bacterial profile of gut microbiota (86).

In 2018, González-Sarrías et al (87) conducted a randomized double-blind clinical trial in a group of obese volunteers in order to explore the impact of pomegranate in restoring the gut microbiota. Compared to baseline levels, the researchers detected a significant change in the bacterial composition of the gut microbiota at the end of the treatment period. Specifically, they found that the administration of 4 capsules per day of pomegranate extract $(450 \mathrm{mg}$ per capsule containing $164 \mathrm{mg}$ of phenolics) increased the richness of those bacteria that improve intestinal immune defenses, such as Bacteroides, Faecalibacterium, Parabacteroides, Odoribacter and Butyricimonas. On the other hand, pomegranate reduced the growth of several pro-inflammatory microorganisms, including Methanobrevibacter, Methanosphaera, Anaerofustis, Parvimonas, Romboutsia and Anaerostipes. González-Sarrías et al (87) further confirmed the prebiotic effects of pomegranate and underlined the potential key role of this functional food in ensuring a healthy intestinal bacterial profile.

Recently, Zhao et al (88) (2019) investigated the modulatory effects of pomegranate pericarp polyphenols on the intestinal microbiota of obese rats. This in vivo study further confirmed the already described anti-inflammatory and antioxidant activities of pomegranate. Indeed, the research group noted that the daily administration of 150 or $300 \mathrm{mg} / \mathrm{kg} / \mathrm{day}$ of pomegranate pericarp polyphenols not only inhibited the release of IL- 6 , TNF- $\alpha$ and IL- $1 \beta$ cytokines, but also enhanced the activity of SOD and GSH-Px enzymes (88). As regards the modulatory effect on gut microbiota, Zhao et al (88) found that the microbial profile was predominantly composed of five phyla, Firmicutes, Bacteroidetes, Proteobacteria, Tenericutes and Actinobacteria. Of note, pericarp polyphenols significantly decreased the Firmicutes/Bacteroidetes ratio, restoring the correct microbial profile of gut microbiota. Overall, the obtained data indicate that also non-edible parts of pomegranate are characterized by bioactive compounds with beneficial properties, suggesting that pericarp phytochemicals may be used to develop novel prebiotic products capable of restoring the normal composition of the gut microbiota (88).

\section{Anticancer effects}

Cancer is defined as a disease with a complex etiology, caused by several endogenous and exogenous factors. It represents the first or second cause of mortality in 112 of 183 countries and ranks third or fourth in a further 23 countries. According to the GLOBOCAN database, there were an estimated 19.3 million new cases of cancer and 10.0 million cancer-related deaths worldwide in 2020, with a $47 \%$ rise of cases expected for 2040 compared to 2020 (28.4 million cases) (89).

Currently, the standard intervention strategies against cancer are based on chemotherapy, immunotherapy and radiotherapy; however, the available anticancer drugs are often limited by severe adverse effects, the development of resistance and consequently no remission of the disease (90).

In this context, it is necessary to develop novel effective anticancer treatments. Over the past few decades, the scientific community has highlighted a positive association between a healthy diet and a low incidence of cancer (91-93). Among several healthy foods, the therapeutic potential of pomegranate has attracted significant interest. Previous studies have also demonstrated that pomegranate and its bioactive compounds can efficiently act on multiple signaling pathways involved in tumorigenesis, angiogenesis, cellular transformation and hyperproliferation $(94,95)$. In addition, as described in the literature, the pomegranate bioactive compounds can modulate cell growth and transcription factors, pro- and anti-apoptotic proteins, protein kinases and adhesion molecules in different types of cancer, such as prostate, bladder, colon, breast, lung and skin cancers $(12,96)$.

For example, in 2015, Mandal and Bishayee (97) examined the anticancer potential of pomegranate phytochemicals in a rat model of breast cancer. First, the research group observed that the daily administration of pomegranate emulsion $(1.0$ or $5.0 \mathrm{~g} / \mathrm{kg})$ significantly reduced the gene expression of estrogen receptor $\alpha($ ER- $\alpha)$ and estrogen receptor $\beta$ (ER- $\beta$ ), both involved in tumor cell proliferation, in a dose-response manner. In addition, to further investigate the mechanisms of action, Mandal and Bishayee (97) focused on the Wnt/ $\beta$-catenin signaling pathway, whose activation is related to cellular proliferation and inhibition of apoptosis. Specifically, they noted that the expression of $\beta$-catenin was 
significantly downregulated in the treated group, indicating that pomegranate was responsible for the inhibition of this signaling pathway. Finally, the researchers evaluated the expression of cyclin D1, an important cofactor in mammary tumorigenesis. Of note, phytochemicals induced a substantial decrease in cyclin D1 expression, suggesting that this cofactor could represent a potential target for the prevention of breast cancer. In summary, the obtained results highlight the potential anticancer effects of pomegranate in rats, suggesting that its bioactive compounds could play a key role in the prevention of breast cancer. However, further studies are necessary to elucidate the anticancer potential of pomegranate and its derivatives (97).

Of note, in 2016, Li et al (98) investigated the effect of phenolic compounds contained in pomegranate leaves extract, such as punicalagin and ellagic acid (39.6 and $32 \mathrm{mg} / \mathrm{g}$, respectively), on a lung carcinoma cell line. First, the researchers observed that the treatment with leaves extracts, especially at the concentration of $100 \mu \mathrm{g} / \mathrm{ml}$, promoted the arrest of the cell cycle in the G2/M phase, causing a significant reduction of tumor cell proliferation and survival. In addition, to further elucidate the mechanisms of action, they evaluated the release of ROS and mitochondrial membrane potential $(\Delta \Psi \mathrm{m})$. Specifically, leaves extracts induced a significant decrease in both in a concentration-dependent manner $(25,50,100$ and $200 \mu \mathrm{g} / \mathrm{ml})$, suggesting that phenols were able to induce the apoptotic process through these inhibitory actions. Finally, Li et al (98) explored the potential effect of leaves phenolic compounds on metastasis. Of note, the scratch test revealed the capability of extracts to attenuate the migration/invasion of tumor cells. This finding was further confirmed by the downregulation in the levels of MMP-2 and MMP-9, whose expression levels are positively associated with the metastatic process. The mentioned in vitro study demonstrated that phytochemicals from pomegranate leaves also had anticancer properties, suggesting that the non-edible parts of this fruit may represent a novel adjuvant for the treatment of lung carcinoma and other cancers (98).

In 2017, Deng et al (99) used a prostate cancer cell line to evaluate whether phytochemicals from pomegranate pericarp had anticancer properties. Deng et al (99) noted that the treatment with pomegranate peel extract, particularly at the concentration of $200 \mu \mathrm{g} / \mathrm{ml}$, was able to decrease tumor cell growth by promoting the apoptotic process. This activity was further demonstrated by the downregulation of B-cell lymphoma 2 (Bcl-2) anti-apoptotic protein and the upregulation of BCL2-associated X protein (Bax) pro-apoptotic protein, both detected following treatment with pericarp extracts. In addition, the research group explored the potential effects of pericarp phenolic compounds on the metastatic process. Notably, they observed that the migratory/invasive ability of the tumor cells was significantly decreased by the pericarp extracts. This inhibition was promoted by the significant reduction in the expression levels of MMP-2 and MMP-9 compared to the control (99). Overall, the data obtained from that study further confirm the anticancer potential of pomegranate and provide the theoretical basis for future investigations on pomegranate and its derivatives as an adjuvant for the treatment of prostate cancer and other diseases (99).
Recently, Ganesan et al (100) (2020) conducted an in vitro study in order to explore the anticancer potential of punicalagin, one of the most abundant phenols contained in pomegranate. Using a colorectal carcinoma cell line, the research group noted that treatment with punicalagin $(0-100 \mu \mathrm{g} / \mathrm{ml})$ led to a significant decrease in tumor cell growth in a concentration-dependent manner. The anti-proliferative effect of punicalagin was further demonstrated by the inhibition of cell viability in the $S$ phase of the cell cycle. At the same time, punicalagin also exhibited pro-apoptotic and autophagic properties, as confirmed by the entry of treated cells into early apoptosis and the degradation of the autophagosome. Finally, in order to better understand the punicalagin mechanisms of action, Ganesan et al (100) detected the expression levels of Annexin A1 (Anx-A1), a protein generally upregulated in colorectal cancer. Specifically, they observed that Anx-A1 was significantly downregulated in the treated cells compared to control, suggesting that punicalagin exerted a selective cytotoxic effect on tumor cells. These results further confirm the anticancer properties of pomegranate and its phytochemicals, suggesting that punicalagin may represent an important start point for the development of a new adjunct in therapy against colorectal cancer (100). The anti-carcinogenic potential of pomegranate and its extracts is summarized in Table III.

\section{Conclusions}

Pomegranate constitutes an important source of a wide variety of bioactive compounds with beneficial properties, including antioxidant, anti-inflammatory, anti-aging, prebiotic and anti-carcinogenic effects, as well as the protective action against metabolic disorders and cardiovascular diseases. As suggested by clinical trials reported in the present review article, it is possible to obtain the aforementioned beneficial effects through the daily consumption of pomegranate extract containing bioactive compounds at clinically relevant doses ranging from about 550 to $650 \mathrm{mg} /$ day of phenolics depending on the study $(69,87)$. In addition, as previously reported by Spilmont et al (61), a daily intake of $250 \mathrm{ml}$ of pomegranate juice is the equivalent nutritional dose required for the maintenance of good health status in an individual of $70 \mathrm{~kg}$ body weight. At the same time, pomegranate and its phytocompounds may represent an adjuvant for the currently available treatments against the previously discussed diseases, able not only to support the therapeutic effects, but also to reduce their side effects. However, further investigations are required to elucidate the mechanisms of action and the synergistic effects of the phytochemicals contained in pomegranate. Moreover, future in vivo and in vitro studies should be undertaken in order to provide a better understanding of pomegranate potential in preventing a wide spectrum of pathological conditions and supporting therapeutic strategies.

\section{Acknowledgements}

Not applicable.

\section{Funding}

No funding was received. 


\section{Availability of data and materials}

The data reported in the manuscript are available from the corresponding author on request. The original contributions presented in the study are publicly available. These data can be found at: www.pubmed.com.

\section{Authors' contributions}

AL, SC and ML conceptualized the study. AL, RS and LF wrote the original draft of the manuscript. RS, LF, GML, GS and ML provided critical revisions. AL, LF, GC, GG and SC prepared the tables, figure and critically analyzed the literature. ML, AL and LF confirm the authenticity of all the raw data. All authors contributed to manuscript revision and all authors have read and approved the final version of the manuscript.

\section{Ethics approval and consent to participate}

Not applicable.

\section{Patient consent for publication}

Not applicable.

\section{Competing interests}

The authors declare that they have no competing interests.

\section{References}

1. Wang D, Özen C, Abu-Reidah IM, Chigurupati S, Patra JK, Horbanczuk JO, Jóźwik A, Tzvetkov NT, Uhrin P and Atanasov AG: Vasculoprotective Effects of Pomegranate (Punica granatum L.). Front Pharmacol 9: 544, 2018.

2. Guerrero-SolanoJA,Jaramillo-MoralesOA,Velázquez-GonzálezC, De la O-Arciniega M, Castañeda-Ovando A, Betanzos-Cabrera G and Bautista M: Pomegranate as a potential alternative of pain management: a review. Plants (Basel) 9: 419, 2020.

3. Wu S and Tian L: Diverse phytochemicals and bioactivities in the ancient fruit and modern functional food pomegranate (Punica granatum). Molecules 22: 1606, 2017.

4. Sharma P, McClees SF and Afaq F: Pomegranate for prevention and treatment of cancer: an update. Molecules 22: 177, 2017.

5. Jurenka JS: Therapeutic applications of pomegranate (Punica granatum L.): A review. Altern Med Rev 13: 128-144, 2008.

6. Saeed M, Naveed M, BiBi J, Kamboh AA, Arain MA, Shah QA, Alagawany M, El-Hack MEA, Abdel-Latif MA, Yatoo MI, et al: The promising pharmacological effects and therapeutic/medicinal applications of Punica granatum L. (pomegranate) as a functional food in humans and animals. Recent Pat Inflamm Allergy Drug Discov 12: 24-38, 2018.

7. Tomás-Barberán FA and Espín JC: Effect of food structure and processing on (poly)phenol-gut microbiota interactions and the effects on human health. Annu Rev Food Sci Technol 10 221-238, 2019.

8. Fischer UA, Carle R and Kammerer DR: Identification and quantification of phenolic compounds from pomegranate (Punica granatum L.) peel, mesocarp, aril and differently produced juices by HPLC-DAD-ESI/MS(n). Food Chem 127: 807-821, 2011.

9. Mena P, Calani L, Dall'Asta C, Galaverna G, García-Viguera C, Bruni R, Crozier A and Del Rio D: Rapid and comprehensive evaluation of (poly)phenolic compounds in pomegranate (Punica granatum L.) juice by UHPLC-MSn. Molecules 17: 14821-14840, 2012.

10. Ismail T, Sestili $P$ and Akhtar S: Pomegranate peel and fruit extracts: A review of potential anti-inflammatory and anti-infective effects. J Ethnopharmacol 143: 397-405, 2012.
11. Shuid AN and Mohamed IN: Pomegranate use to attenuate bone loss in major musculoskeletal diseases: An evidence-based review. Curr Drug Targets 14: 1565-1578, 2013.

12. Turrini E, Ferruzzi L and Fimognari C: Potential effects of pomegranate polyphenols in cancer prevention and therapy. Oxid Med Cell Longev 2015: 938475, 2015.

13. Kalaycıoğlu $Z$ and Erim FB: Total phenolic contents, antioxidant activities, and bioactive ingredients of juices from pomegranate cultivars worldwide. Food Chem 221: 496-507, 2017.

14. Danesi F and Ferguson LR: Could pomegranate juice help in the control of inflammatory diseases? Nutrients 9: 958, 2017.

15. Razani Z, Dastani M and Kazerani HR: Cardioprotective Effects of pomegranate (Punica granatum) juice in patients with ischemic heart disease. Phytother Res 31: 1731-1738, 2017.

16. Viuda-Martos M, Fernández-López J and Pérez-Álvarez JA: Pomegranate and its many functional components as related to human health: A review. Compr Rev Food Sci Food Saf 9: 635-654, 2010.

17. Moga MA, Dimienescu OG, Bălan A, Dima L, Toma SI, Bîgiu NF and Blidaru A: Pharmacological and therapeutic properties of Punica granatum phytochemicals: possible roles in breast cancer. Molecules 26: 1054, 2021.

18. Pirzadeh M, Caporaso N, Rauf A, Shariati MA, Yessimbekov Z, Khan MU, Imran M and Mubarak MS: Pomegranate as a source of bioactive constituents: A review on their characterization, properties and applications. Crit Rev Food Sci Nutr 61: 982-999, 2021.

19. Krueger DA: Composition of pomegranate juice. J AOAC Int 95: 163-168, 2012.

20. Fahmy H, Hegazi N, El-Shamy S and Farag MA: Pomegranate juice as a functional food: A comprehensive review of its polyphenols, therapeutic merits, and recent patents. Food Funct 11: 5768-5781, 2020.

21. Singh B, Singh JP, Kaur A and Singh N: Phenolic compounds as beneficial phytochemicals in pomegranate (Punica granatum $\mathrm{L}$.) peel: A review. Food Chem 261: 75-86, 2018.

22. El-Hadary AE and Ramadan MF: Phenolic profiles, antihyperglycemic, antihyperlipidemic, and antioxidant properties of pomegranate (Punica granatum) peel extract. J Food Biochem 43: e12803, 2019.

23. Fourati M, Smaoui S, Hlima HB, Elhadef K, Braïek OB, Ennouri K, Mtibaa AC and Mellouli L: Bioactive compounds and pharmacological potential of pomegranate (Punica granatum) seeds - a review. Plant Foods Hum Nutr 75: 477-486, 2020.

24. Li G, Chen M, Chen J, Shang Y, Lian X, Wang P, Lei H and Ma Q: Chemical composition analysis of pomegranate seeds based on ultra-high-performance liquid chromatography coupled with quadrupole-Orbitrap high-resolution mass spectrometry. J Pharm Biomed Anal 187: 113357, 2020.

25. Elfalleh W, Hannachi H, Tlili N, Yahia Y, Nasri N and Ferchichi A: Total phenolic content and antioxidant activities of pomegranate peel, seed, leaf and flower. J Med Plants Res 6: 4724-4730, 2012.

26. Sreedevi P, Vijayalakshmi $K$ and Venkataeswari R: Phytochemical evaluation of Punica granatum L. leaf extract. Int J Curr Pharm Res 9: 14-18, 2017.

27. Di Stefano V, Pitonzo R, Novara ME, Bongiorno D, Indelicato S, Gentile C, Avellone G, Bognanni R, Scandurra S and Melilli MG: Antioxidant activity and phenolic composition in pomegranate (Punica granatum L.) genotypes from south Italy by UHPLC-Orbitrap-MS approach. J Sci Food Agric 99: 1038-1045, 2019.

28. Russo M, Fanali C, Tripodo G, Dugo P, Muleo R, Dugo L, De Gara L and Mondello L: Analysis of phenolic compounds in different parts of pomegranate (Punica granatum) fruit by HPLC-PDA-ESI/MS and evaluation of their antioxidant activity: Application to different Italian varieties. Anal Bioanal Chem 410: 3507-3520, 2018.

29. Seeram NP, Adams LS, Henning SM, Niu Y, Zhang Y, Nair MG and Heber D: In vitro antiproliferative, apoptotic and antioxidant activities of punicalagin, ellagic acid and a total pomegranate tannin extract are enhanced in combination with other polyphenols as found in pomegranate juice. J Nutr Biochem 16: 360-367, 2005.

30. Johanningsmeier SD and Harris GK: Pomegranate as a functional food and nutraceutical source. Annu Rev Food Sci Technol 2: 181-201, 2011.

31. Hussain T, Tan B, Yin Y, Blachier F, Tossou MC and Rahu N: Oxidative stress and inflammation: what polyphenols can do for us? Oxid Med Cell Longev 2016: 7432797, 2016. 
32. Rozenberg O, Howell A and Aviram M: Pomegranate juice sugar fraction reduces macrophage oxidative state, whereas white grape juice sugar fraction increases it. Atherosclerosis 188: $68-76,2006$

33. Seeram NP, Aviram M, Zhang Y, Henning SM, Feng L, Dreher M and Heber D: Comparison of antioxidant potency of commonly consumed polyphenol-rich beverages in the United States. J Agric Food Chem 56: 1415-1422, 2008.

34. Gómez-Caravaca AM, Verardo V, Toselli M, Segura-Carretero A Fernández-Gutiérrez A and Caboni MF: Determination of the major phenolic compounds in pomegranate juices by HPLC-DAD-ESI-MS. J Agric Food Chem 61: 5328-5337, 2013.

35. Derakhshan Z, Ferrante M, Tadi M, Ansari F, Heydari A, Hosseini MS, Conti GO and Sadrabad EK: Antioxidant activity and total phenolic content of ethanolic extract of pomegranate peels, juice and seeds. Food Chem Toxicol 114: 108-111, 2018

36. Tugcu B, Nacaroglu SA, Gedikbasi A, Uhri M, Acar N and Ozdemir H: Protective effect of pomegranate juice on retinal oxidative stress in streptozotocin-induced diabetic rats. Int J Ophthalmol 10: 1662-1668, 2017

37. Liu C, Guo H, DaSilva NA, Li D, Zhang K, Wan Y, Gao XH, Chen HD, Seeram NP and Ma H: Pomegranate (Punica granatum) phenolics ameliorate hydrogen peroxide-induced oxidative stress and cytotoxicity in human keratinocytes. J Funct Foods 54: 559-567, 2019.

38. Morittu VM, Mastellone V, Tundis R, Loizzo MR, Tudisco R, Figoli A, Cassano A, Musco N, Britti D, Infascelli F, et al: Antioxidant, biochemical, and in-life effects of Punica granatum L. natural juice vs. clarified juice by polyvinylidene fluoride membrane. Foods 9: 242, 2020.

39. Lin Y, Jiang M, Chen W, Zhao T and Wei Y: Cancer and ER stress: Mutual crosstalk between autophagy, oxidative stress and inflammatory response. Biomed Pharmacother 118: 109249, 2019.

40. Ahmadi A, Polyak S and Draganov PV: Colorectal cancer surveillance in inflammatory bowel disease: The search continues. World J Gastroenterol 15: 61-66, 2009.

41. Nasef NA, Mehta S and Ferguson LR: Susceptibility to chronic inflammation: An update. Arch Toxicol 91: 1131-1141, 2017.

42. Calder PC, Albers R, Antoine JM, Blum S, Bourdet-Sicard R, Ferns GA, Folkerts G, Friedmann PS, Frost GS, Guarner F, et al: Inflammatory disease processes and interactions with nutrition. Br J Nutr 101 (Suppl 1): S1-S45, 2009.

43. Zhao CN, Meng X, Li Y, Li S, Liu Q, Tang GY and Li HB Fruits for prevention and treatment of cardiovascular diseases. Nutrients 9: 598, 2017.

44. Salas-Salvadó J, Becerra-Tomás N, García-Gavilán JF, Bulló M and Barrubés L: Mediterranean diet and cardiovascular disease prevention: what do we know? Prog Cardiovasc Dis 61: 62-67, 2018

45. Davinelli S, Maes M, Corbi G, Zarrelli A, Willcox DC and Scapagnini G: Dietary phytochemicals and neuro-inflammaging: From mechanistic insights to translational challenges. Immun Ageing 13: 16, 2016.

46. Serino A and Salazar G: Protective role of polyphenols against vascular inflammation, aging and cardiovascular disease. Nutrients 11: 53, 2018

47. Du L, Li J, Zhang X, Wang L and Zhang W: Pomegranate peel polyphenols inhibits inflammation in LPS-induced RAW264.7 macrophages via the suppression of MAPKs activation. J Funct Foods 43: 62-69, 2018.

48. Mastrogiovanni F, Mukhopadhya A, Lacetera N, Ryan MT, Romani A, Bernini R and Sweeney T: Anti-inflammatory effects of pomegranate peel extracts on in vitro human intestinal Caco-2 cells and ex vivo porcine colonic tissue explants. Nutrients 11 : $548,2019$.

49. Pepe G, Rapa SF, Salviati E, Bertamino A, Auriemma G, Cascioferro S, Autore G, Quaroni A, Campiglia P and Marzocco S: Bioactive polyphenols from pomegranate juice reduce 5-fluorouracil-induced intestinal mucositis in intestinal epithelial cells. Antioxidants 9: 699, 2020.

50. Rose MR: Adaptation, aging, and genomic information. Aging (Albany NY) 1: 444-450, 2009.

51. Johnson IP: Age-related neurodegenerative disease research needs aging models. Front Aging Neurosci 7: 168, 2015.

52. Khosla S, Farr JN and Kirkland JL: Inhibiting cellular senescence: a new therapeutic paradigm for age-related osteoporosis. J Clin Endocrinol Metab 103: 1282-1290, 2018.

53. Brettschneider J, Del Tredici K, Lee VM and Trojanowski JQ: Spreading of pathology in neurodegenerative diseases: A focus on human studies. Nat Rev Neurosci 16: 109-120, 2015.
54. Kovacs GG: Molecular pathology of neurodegenerative diseases: Principles and practice. J Clin Pathol 72: 725-735, 2019.

55. Braidy N, Essa MM, Poljak A, Selvaraju S, Al-Adawi S Manivasagm T, Thenmozhi AJ, Ooi L, Sachdev P and Guillemin GJ: Consumption of pomegranates improves synaptic function in a transgenic mice model of Alzheimer's disease. Oncotarget 7: 64589-64604, 2016

56. Kujawska M, Jourdes M, Kurpik M, Szulc M, Szaefer H, Chmielarz P, Kreiner G, Krajka-Kuźniak V, Mikołajczak PŁ, Teissedre PL, et al: Neuroprotective effects of pomegranate juice against parkinson's disease and presence of ellagitannins-derived metabolite-urolithin a-in the brain. Int J Mol Sci 21: 202, 2019.

57. Lock CA, Lecouturier J, Mason JM and Dickinson HO: Lifestyle interventions to prevent osteoporotic fractures: A systematic review. Osteoporos Int 17: 20-28, 2006.

58. Sandhu SK and Hampson G: The pathogenesis, diagnosis, investigation and management of osteoporosis. J Clin Pathol 64: 1042-1050, 2011

59. Harvey N, Dennison E and Cooper C: Osteoporosis: Impact on health and economics. Nat Rev Rheumatol 6: 99-105, 2010.

60. Schulman RC, Weiss AJ and Mechanick JI: Nutrition, bone, and aging: An integrative physiology approach. Curr Osteoporos Rep 9: 184-195, 2011.

61. Spilmont M, Léotoing L, Davicco MJ, Lebecque P, Mercier S, Miot-Noirault E, Pilet P, Rios L, Wittrant Y and Coxam V: Pomegranate and its derivatives can improve bone health through decreased inflammation and oxidative stress in an animal model of postmenopausal osteoporosis. Eur J Nutr 53 : $1155-1164,2014$

62. Wang W, Bai J, Zhang W, Ge G, Wang Q, Liang X, Li N, Gu Y, $\mathrm{Li} \mathrm{M}, \mathrm{Xu} \mathrm{W}$, et al: Protective effects of punicalagin on osteoporosis by inhibiting osteoclastogenesis and inflammation via the nf- $\mathrm{kb}$ and mapk pathways. Front Pharmacol 11: 696, 2020.

63. Eaton CB: Traditional and emerging risk factors for cardiovascular disease. Prim Care 32: 963-976, vii, 2005.

64. Jagannathan R, Patel SA, Ali MK and Narayan KMV: Global updates on cardiovascular disease mortality trends and attribution of traditional risk factors. Curr Diab Rep 19: 44, 2019.

65. Eilat-Adar S, Sinai T, Yosefy C and Henkin Y: Nutritional recommendations for cardiovascular disease prevention. Nutrients 5: 3646-3683, 2013

66. Wang X, Ouyang Y, Liu J, Zhu M, Zhao G, Bao W and Hu FB: Fruit and vegetable consumption and mortality from all causes, cardiovascular disease, and cancer: Systematic review and dose-response meta-analysis of prospective cohort studies BMJ 349: g4490, 2014.

67. Chong MF, Macdonald R and Lovegrove JA: Fruit polyphenols and CVD risk: A review of human intervention studies. Br J Nutr 104 (Suppl 3): S28-S39, 2010

68. Grassi D, Desideri G and Ferri C: Flavonoids: Antioxidants against atherosclerosis. Nutrients 2: 889-902, 2010.

69. Stockton A, Farhat G, McDougall GJ and Al-Dujaili EAS: Effect of pomegranate extract on blood pressure and anthropometry in adults: A double-blind placebo-controlled randomised clinical trial. J Nutr Sci 6: e39, 2017

70. Estrada-Luna D, Martínez-Hinojosa E, Cancino-Diaz JC, Belefant-Miller H, López-Rodríguez G and Betanzos-Cabrera G: Daily supplementation with fresh pomegranate juice increases paraoxonase 1 expression and activity in mice fed a high-fat diet. Eur J Nutr 57: 383-389, 2018

71. Gaidukov L and Tawfik DS: High affinity, stability, and lactonase activity of serum paraoxonase PON1 anchored on HDL with ApoA-I. Biochemistry 44: 11843-11854, 2005.

72. Gouédard C, Barouki R and Morel Y: Dietary polyphenols increase paraoxonase 1 gene expression by an aryl hydrocarbon receptor-dependent mechanism. Mol Cell Biol 24: 5209-5222, 2004.

73. Huang TH, Peng G, Kota BP, Li GQ, Yamahara J, Roufogalis BD and Li Y: Pomegranate flower improves cardiac lipid metabolism in a diabetic rat model: Role of lowering circulating lipids. $\mathrm{Br} \mathrm{J}$ Pharmacol 145: 767-774, 2005

74. Bagri P, Ali M, Aeri V, Bhowmik M and Sultana S: Antidiabetic effect of Punica granatum flowers: Effect on hyperlipidemia, pancreatic cells lipid peroxidation and antioxidant enzymes in experimental diabetes. Food Chem Toxicol 47: 50-54, 2009.

75. Les F, Arbonés-Mainar JM, Valero MS and López V: Pomegranate polyphenols and urolithin A inhibit $\alpha$-glucosidase, dipeptidyl peptidase-4, lipase, triglyceride accumulation and adipogenesis related genes in 3T3-L1 adipocyte-like cells. J Ethnopharmacol 220: 67-74, 2018 
76. Blaut $\mathrm{M}$ and Clavel $\mathrm{T}$ : Metabolic diversity of the intestinal microbiota: Implications for health and disease. J Nutr 137 (Suppl 2): 751S-755S, 2007.

77. Qin J, Li R, Raes J, Arumugam M, Burgdorf KS, Manichanh C, Nielsen T, Pons N, Levenez F, Yamada T, et al; MetaHIT Consortium: A human gut microbial gene catalogue established by metagenomic sequencing. Nature 464: 59-65, 2010.

78. Belkaid Y and Hand TW: Role of the microbiota in immunity and inflammation. Cell 157: 121-141, 2014.

79. Cani PD, Osto M, Geurts L and Everard A: Involvement of gut microbiota in the development of low-grade inflammation and type 2 diabetes associated with obesity. Gut Microbes 3: 279-288, 2012.

80. Karlsson F, Tremaroli V, Nielsen J and Bäckhed F: Assessing the human gut microbiota in metabolic diseases. Diabetes 62 $3341-3349,2013$.

81. Scott KP, Antoine JM, Midtvedt $\mathrm{T}$ and van Hemert $\mathrm{S}$ Manipulating the gut microbiota to maintain health and treat disease. Microb Ecol Health Dis 26: 25877, 2015.

82. Dueñas M, Muñoz-González I, Cueva C, Jiménez-Girón A Sánchez-Patán F, Santos-Buelga C, Moreno-Arribas MV and Bartolomé B: A survey of modulation of gut microbiota by dietary polyphenols. BioMed Res Int 2015: 850902, 2015.

83. Holscher HD: Dietary fiber and prebiotics and the gastrointestinal microbiota. Gut Microbes 8: 172-184, 2017.

84. Bialonska D, Kasimsetty SG, Schrader KK and Ferreira D: The effect of pomegranate (Punica granatum L.) byproducts and ellagitannins on the growth of human gut bacteria. J Agric Food Chem 57: 8344-8349, 2009

85. Finegold SM, Summanen PH, Corbett K, Downes J, Henning SM and Li Z: Pomegranate extract exhibits in vitro activity against Clostridium difficile. Nutrition 30: 1210-1212, 2014.

86. Li Z, Summanen PH, Komoriya T, Henning SM, Lee RP, Carlson E, Heber D and Finegold SM: Pomegranate ellagitannins stimulate growth of gut bacteria in vitro: Implications for prebiotic and metabolic effects. Anaerobe 34: 164-168, 2015.

87. González-Sarrías A, Romo-Vaquero M, García-Villalba R, Cortés-Martín A, Selma MV and Espín JC: The endotoxemia marker lipopolysaccharide-binding protein is reduced in overweight-obese subjects consuming pomegranate extract by modulating the gut microbiota: a randomized clinical trial. Mol Nutr Food Res 62: e1800160, 2018.

88. Zhao R, Long X, Yang J, Du L, Zhang X, Li J and Hou C: Pomegranate peel polyphenols reduce chronic low-grade inflammatory responses by modulating gut microbiota and decreasing colonic tissue damage in rats fed a high-fat diet. Food Funct 10: 8273-8285, 2019.
89. Sung H, Ferlay J, Siegel RL, Laversanne M, Soerjomataram I, Jemal A and Bray F: Global cancer statistics 2020: GLOBOCAN estimates of incidence and mortality worldwide for 36 cancers in 185 countries. CA Cancer J Clin: Feb 4, 2021 (Epub ahead of print).

90. Vasan N, Baselga J and Hyman DM: A view on drug resistance in cancer. Nature 575: 299-309, 2019.

91. Barnard RJ: Prevention of cancer through lifestyle changes. Evid Based Complement Alternat Med 1: 233-239, 2004.

92. Key TJ, Schatzkin A, Willett WC, Allen NE, Spencer EA and Travis RC: Diet, nutrition and the prevention of cancer. Public Health Nutr 7 (1A): 187-200, 2004.

93. Turati F, Rossi M, Pelucchi C, Levi F and La Vecchia C: Fruit and vegetables and cancer risk: A review of southern European studies. Br J Nutr 113 (Suppl 2): S102-S110, 2015.

94. Khan N, Afaq F and Mukhtar H: Cancer chemoprevention through dietary antioxidants: Progress and promise. Antioxid Redox Signal 10: 475-510, 2008.

95. Faria A and Calhau C: The bioactivity of pomegranate: Impact on health and disease. Crit Rev Food Sci Nutr 51: 626-634, 2011

96. Kandylis P and Kokkinomagoulos E: Food applications and potential health benefits of pomegranate and its derivatives. Foods 9: 122, 2020

97. Mandal A and Bishayee A: Mechanism of breast cancer preventive action of pomegranate: disruption of estrogen receptor and $\mathrm{Wnt} / \beta$-catenin signaling pathways. Molecules 20: 22315-22328, 2015.

98. Li Y, Yang F, Zheng W, Hu M, Wang J, Ma S, Deng Y, Luo Y, Ye T and Yin W: Punica granatum (pomegranate) leaves extract induces apoptosis through mitochondrial intrinsic pathway and inhibits migration and invasion in non-small cell lung cancer in vitro. Biomed Pharmacother 80: 227-235, 2016.

99. Deng Y, Li Y, Yang F, Zeng A, Yang S, Luo Y, Zhang Y, Xie Y, Ye T, Xia Y, et al: The extract from Punica granatum (pomegranate) peel induces apoptosis and impairs metastasis in prostate cancer cells. Biomed Pharmacother 93: 976-984, 2017.

100. Ganesan T, Sinniah A, Chik Z and Alshawsh MA: Punicalagin regulates apoptosis-autophagy switch via modulation of annexin A1 in colorectal cancer. Nutrients 12: 2430, 2020.

This work is licensed under a Creative Commons Attribution-NonCommercial-NoDerivatives 4.0 International (CC BY-NC-ND 4.0) License. 